\section{Exercise-induced visual loss associated with advanced glaucoma in young adults}

\begin{abstract}
Purpose To highlight the phenomenon of exercise-induced visual loss associated with advanced glaucoma and to discuss the possible underlying mechanisms.

Methods Three young adult patients with congenital or juvenile-onset glaucoma presenting with visual loss which occurred during exercise underwent ophthalmic examination. In 2 cases, visual function parameters, including visual fields (Humphrey full threshold perimetry) were measured before and after exercise.

Results All patients clearly described visual loss during exercise. In the 2 cases in which data were available, significant impairment in central visual acuity and reduced foveal sensitivity and mean deviation on visual field analysis occurred during exercise of mild to moderate intensity with complete or near complete recovery of visual function upon cessation of exercise.

Conclusion Young patients with advanced glaucomatous optic neuropathy should be questioned regarding exercise-induced visual disturbance. We hypothesise that a 'vascular steal' is the likely mechanism underlying this phenomenon. Patients should be advised to limit activities which induce their symptoms, and therapeutic measures to promote ocular blood flow should be considered.
\end{abstract}

Key words Exercise, Glaucoma, Juvenile

Mr Peter Shah

Birmingham and Midland Eye Centre

City Hospital NHS Trust

Dudley Road

Birmingham B18 7QH, UK

The authors who have undertaken this work have received funding from the NHS Executive; the views expressed in this publication are those of the authors and not necessarily those of the NHS Executive

Received: 29 August 2000 Accepted in revised form: 5 February 2001
P. SHAH, K.W. WHITTAKER,

A.P. WELLS, P.T. KHAW

\section{Case reports}

Case 1

A 33-year-old woman with advanced glaucoma complained of decreased vision in both eyes when exercising. Specifically, she described reduced central visual acuity and generalised dimming of her visual field when performing moderately strenuous activity such as jogging. She also admitted to similar symptoms whilst eating a large meal or drinking alcohol. Her symptoms were often so severe that although she could read the menu at the start of the meal she would be unable to read the dessert menu after the main course. She denied other ocular or systemic symptoms and her general health was good. She was on no systemic medication.

Advanced juvenile-onset glaucoma, with intraocular pressures of $40 \mathrm{mmHg}$ in both eyes, had been diagnosed at 15 years of age. Three goniotomies in the right eye and two in the left had been performed at approximately 15 years of age and, following a deterioration in intraocular pressure control, she underwent a left trabeculectomy aged 29 years. Her glaucoma had since been stable, and she was using guttae levobunolol $0.5 \%$ b.d. and pilocarpine $2 \%$ q.d.s. to the right eye only.

On examination, there was a cystic trabeculectomy bleb in the left eye and severe optic disc cupping (vertical cup:disc ratio 0.95) in both eyes. There were no signs of pigment dispersion syndrome, and the anterior chamber drainage angles were wide open. The following parameters were measured before, immediately after, and $2 \mathrm{~h}$ following a period of moderate exercise (20 sit-ups followed by a brisk walk up 3 flights of stairs): visual acuity (Snellen and near), Ishihara colour vision, intraocular pressure, computerised perimetry fields, heart rate, blood pressure and temperature (axillary). Visual acuities and visual field parameters decreased significantly immediately after exercising and returned to baseline levels within $2 \mathrm{~h}$. The intraocular pressures decreased slightly with exercise (Table 1, Fig. 1). Her temperature increased by $0.2^{\circ} \mathrm{C}$, but there was no change in heart rate or blood pressure (Table 2). 
General examination and neurological assessment prior to exercise were normal. She was advised to abstain from high-intensity exercise and prescribed aspirin $75 \mathrm{mg}$ daily.

Four years after she initially reported symptoms of exercise-induced visual loss, her visual function remained stable.

\section{Case 2}

A 37-year-old woman complained of blurred vision which she first noticed when chasing after her 3-year-old child and which subsequently occurred during light exercise. She also experienced similar symptoms on eating a large meal. She denied other ocular or systemic symptoms. Her general health was good and she was on no systemic medication.

She had advanced open angle glaucoma in both eyes secondary to bilateral Sturge-Weber syndrome. She had previously undergone left cyclodialysis in 1959, a left goniotomy in 1964, a left trephine in 1965, a left intrascleral diathermy in 1969, and a left cyclocryotherapy in 1970. Her right eye had undergone a trabeculectomy with beta radiation in 1988. Her intraocular pressures had been well controlled for several years on guttae levobunolol b.d. to both eyes.

On examination, there was a cystic trabeculectomy bleb in the right eye and severe optic disc cupping (vertical cup:disc ratio 0.95) in both eyes. There were no signs of pigment dispersion syndrome, and the anterior chamber drainage angles were open. Visual acuity (Snellen), intraocular pressures, computerised perimetry fields and temperature (axillary) were tested before and after exercise (10 sit-ups). The visual acuities and visual field parameters decreased significantly immediately on exercising and returned to near baseline levels after $1 \mathrm{~h}$. For logistical reasons it was necessary to perform a combination of 24-2 and 10-2 Humphrey visual fields in this patient. There was no change in intraocular pressure (Table 1, Fig. 2).

A general examination and neurological assessment prior to exercise were normal.

\section{Case 3}

A 29-year-old woman reported blurred vision when chasing her young daughter, aged 4 years. She had also noticed similar symptoms on rapid rotational head movements and on lifting her head quickly from a chin-down position. She denied other ocular or systemic symptoms and her general health was good.

On examination, her right visual acuity was $6 / 24$. The intraocular pressure was $18 \mathrm{mmHg}$, the optic disc was severely cupped and her visual field had severe generalised constriction which encroached to within $5^{\circ}$ of fixation. She had advanced glaucomatous optic neuropathy in both eyes secondary to primary congenital glaucoma which had been diagnosed at the age of 3 years. Intraocular pressures at presentation were $37 \mathrm{mmHg}$ in the right eye and $44 \mathrm{mmHg}$ in the left. The intraocular pressure in her left eye had been refractory to treatment and this large painful buphthalmic eye had been enucleated in childhood following a complicated cataract extraction. She had undergone multiple surgeries including goniotomy and trabeculectomy to the right eye as a child, and a trabeculectomy as a teenager in 1994. Her glaucoma had been stable for several years on topical medical treatment (guttae levobunolol b.d.).

\section{Discussion}

Ocular function may be affected by exercise in different ways. For example, it has been shown that intraocular pressure is temporarily lowered during aerobic and anaerobic activity in normal adults and those with primary open-angle glaucoma. ${ }^{7}$ This reduction is proportional to the intensity of exercise and is greater in sedentary subjects. ${ }^{8}$ Whilst the pathophysiology is poorly understood, there is a correlation with increased blood lactate levels. ${ }^{8}$ Conversely, exercise may lead to raised intraocular pressure, sometimes with blurring of vision, in patients with pigment dispersion syndrome. ${ }^{9}$ This is caused by active pigment dispersion during activity with deposition in the trabecular meshwork.

Exercise may also have an effect on visual field sensitivity. Elderly male athletes have been shown to have significantly more sensitive visual fields compared with a control group. ${ }^{10}$ However, a study of young, visually normal subjects showed exercise to have no effect on visual field sensitivity. ${ }^{11}$

The first report of decreased vision with exercise was first recognised by Uhthoff in 1890 in patients with optic neuritis and multiple sclerosis. ${ }^{1}$ However, it was not until the 1940s that this phenomenon came to be appreciated by other workers. ${ }^{12-14}$ Now, as a presenting

Table 1. Visual function parameters before and after exercise

\begin{tabular}{|c|c|c|c|c|c|c|}
\hline & \multicolumn{2}{|c|}{$\begin{array}{l}\text { Visual acuity } \\
\text { (Snellen) }\end{array}$} & \multirow[t]{2}{*}{$\begin{array}{l}\text { Foveal sensitivity } \\
\qquad(\mathrm{db})\end{array}$} & \multirow[t]{2}{*}{$\begin{array}{l}\text { Mean deviation } \\
(\mathrm{db})\end{array}$} & \multicolumn{2}{|c|}{$\begin{array}{c}\text { Intraocular pressure } \\
(\mathrm{mmHg})\end{array}$} \\
\hline & OD & OS & & & OD & OS \\
\hline \multicolumn{7}{|l|}{ Case 1} \\
\hline Before exercise & $2 / 9+5$ & $2 / 36+$ & 21 & -11.82 & 12 & 11 \\
\hline Immediately after exercise & $2 / 12-$ & $2 / 60+$ & 9 & -14.00 & 8 & 7 \\
\hline Two hours after exercise & $2 / 9-$ & $? 2 / 36+$ & 19 & -11.91 & 13 & 9 \\
\hline \multicolumn{7}{|l|}{ Case 2} \\
\hline Before exercise & $6 / 12+$ & $6 / 24$ & 32 & -31.45 & 16 & 16 \\
\hline Immediately after exercise & CFs & CFs & 15 & -32.96 & 16 & 16 \\
\hline One hour after exercise & $6 / 12$ & $6 / 24$ & 27 & $\mathrm{~N} / \mathrm{A}$ & 16 & 16 \\
\hline
\end{tabular}




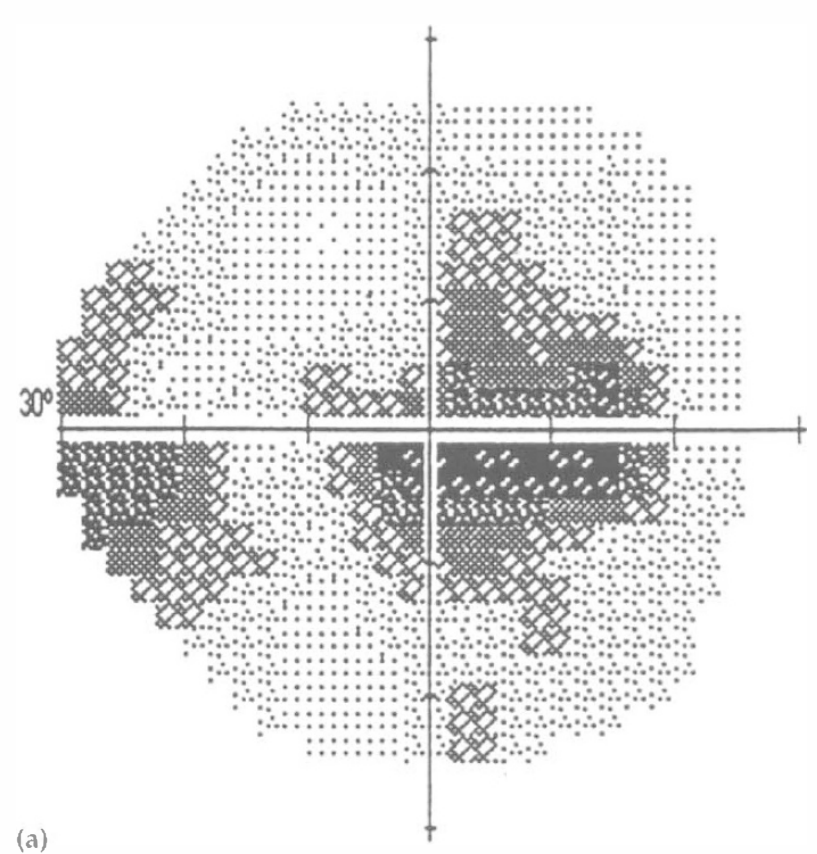

(a)

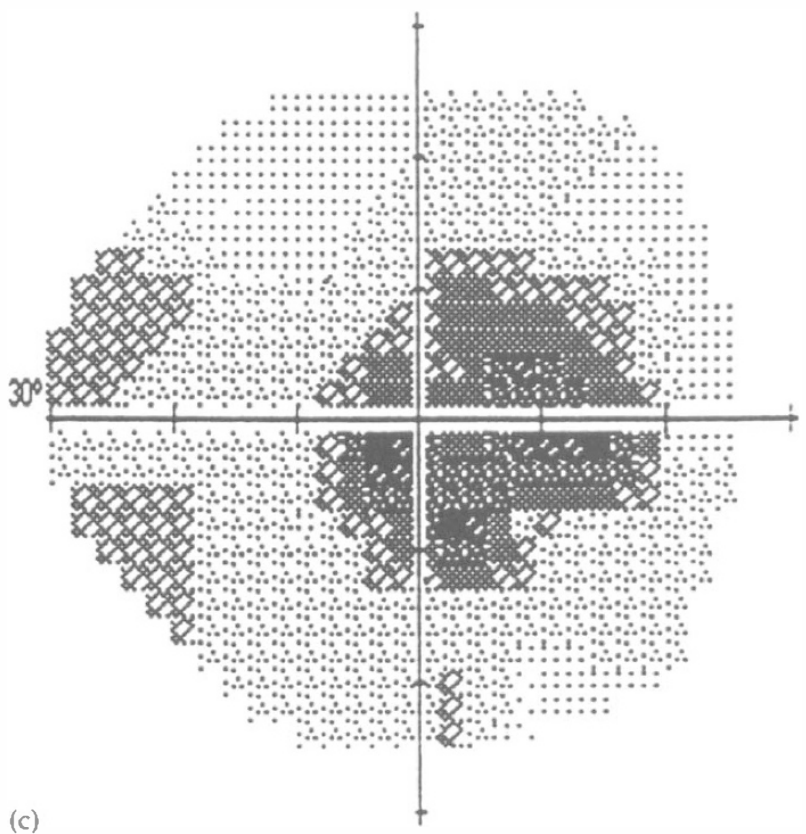

complaint or as a sequela of optic neuritis, it is established as an important risk factor for multiple sclerosis. The level of exercise required to induce visual loss may be very mild; Uhthoff described it in one patient walking around a room. When it does occur, a mild degree of optic atrophy is usually present. The visual loss is occasionally bilateral and may develop as early as $30 \mathrm{~s}$ after the onset of exercise. In most patients, visual function returns to normal levels within a few minutes of cessation of exercise. $^{2}$

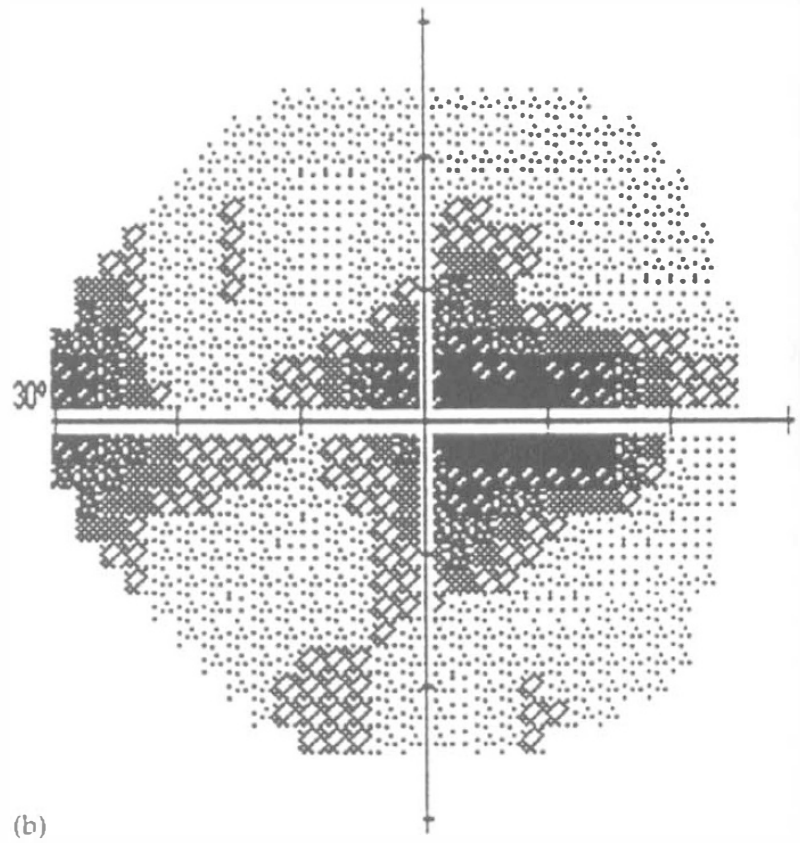

Fig. 1. Case 1. Humphrey full threshold 24-2 visual fields. (a) Before exercise. (b) Immediately after exercise. (c) Two hours after exercise.

Since its original description, Uhthoff's symptom has been recognised in association with other optic neuropathies, including compression by tumour or Friedreich's ataxia, ${ }^{3}$ chloramphenicol optic neuropathy, ${ }^{5}$ Leber's hereditary optic neuropathy ${ }^{4}$ and posterior ciliary artery insufficiency. ${ }^{6}$ Chloramphenicol optic neuropathy, characterised by reduced visual acuity, dyschromatopsia and fundus changes, has been reported to be associated with transient worsening of vision after strenuous exercise in the acute stage of the disease. In

Table 2. Systemic parameters before and after exercise for case 1

\begin{tabular}{lccc}
\hline & Blood pressure $(\mathrm{mmHg})$ & Temperature $\left({ }^{\circ} \mathrm{C}\right)$ & Heart rate $($ beats $/ \mathrm{min})$ \\
\hline Before exercise & $130 / 80$ & 36.9 & 70 \\
Immediately after exercise & $130 / 80$ & 37.1 & 90 \\
Two hours after exercise & $130 / 80$ & 36.9 & 70 \\
\hline
\end{tabular}




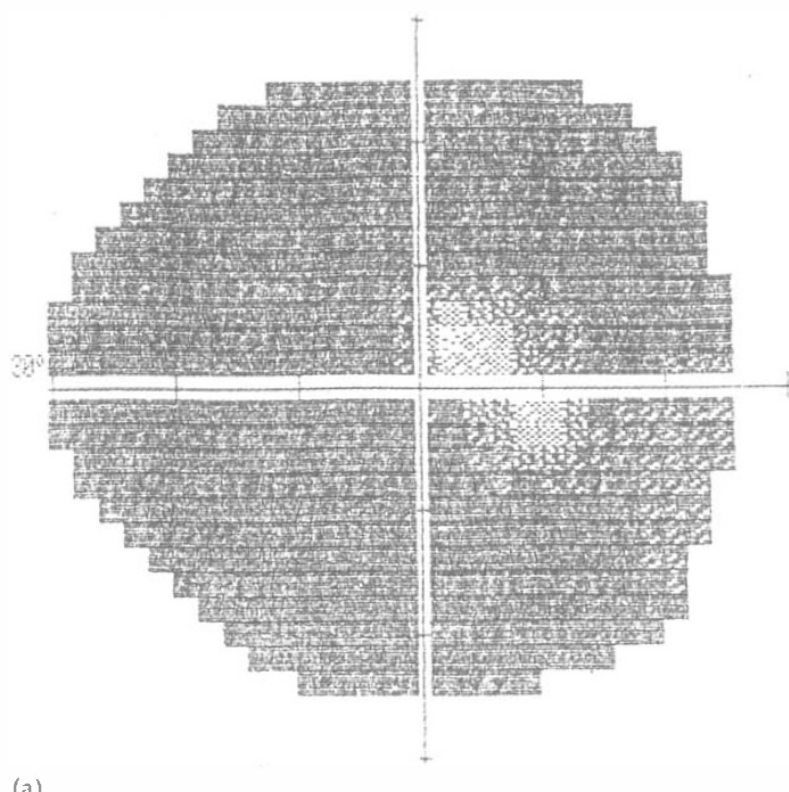

(a)

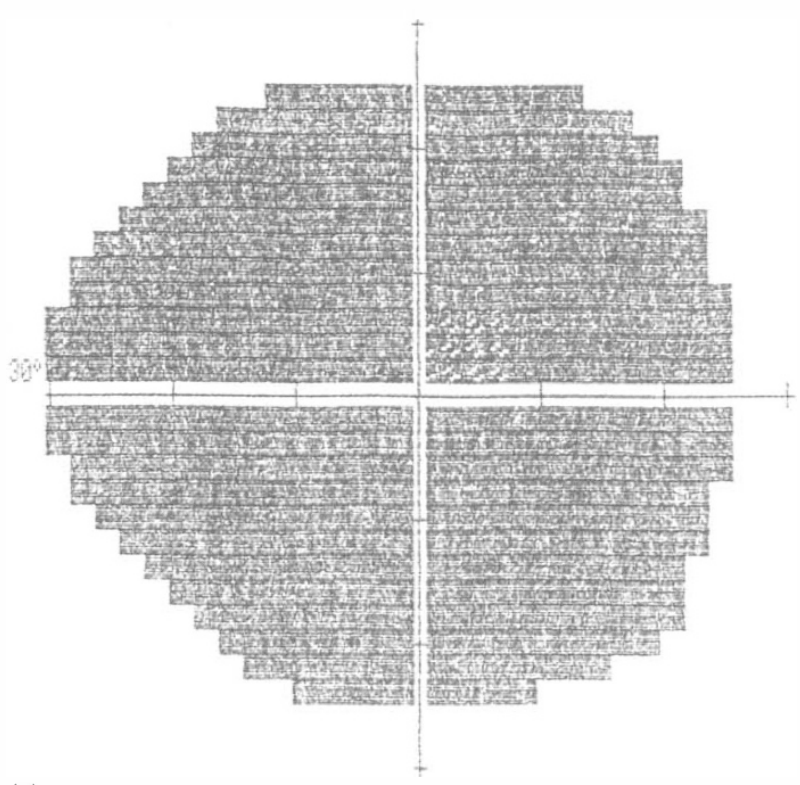

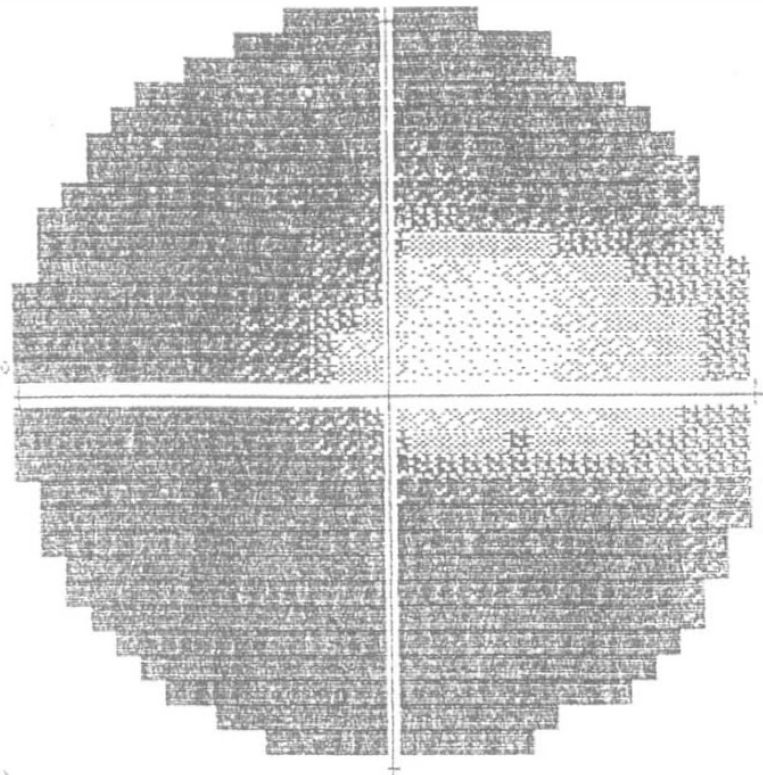

(b)

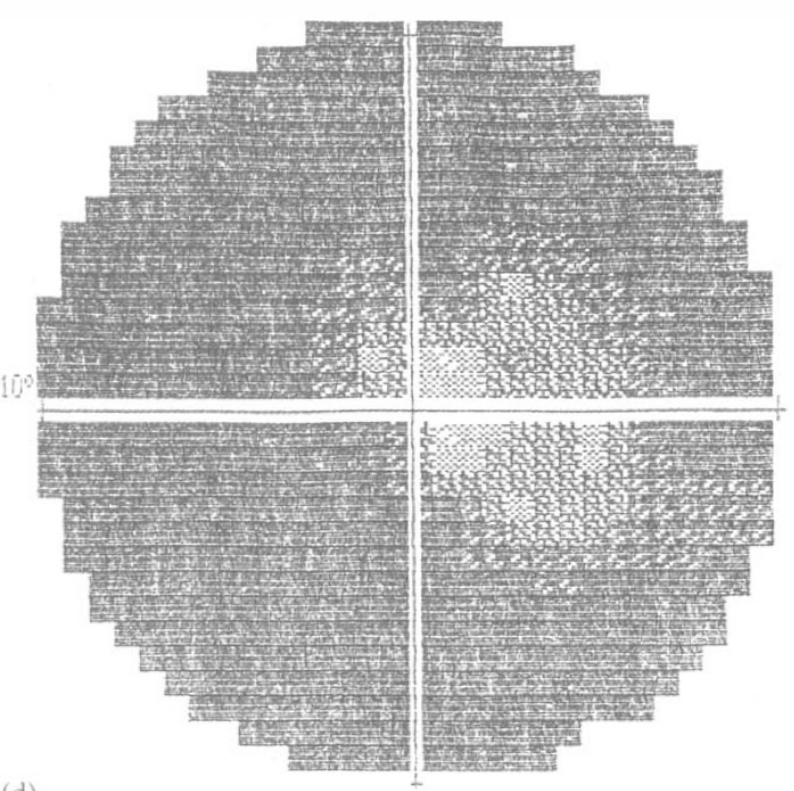

Fig. 2. Case 2. Humphrey full threshold visual fields. (a) Before exercise (24-2). (b) Before exercise (10-2). (c) Immediately after exercise (24-2). (d) One hour after exercise (10-2).

one patient with Leber's optic neuropathy, blurred vision during exercise was present before the onset of permanent visual loss. In another patient with posterior ciliary artery insufficiency secondary to internal carotid artery stenosis monocular visual blurring occurred after vigorous exercise and on turning his head to one side.,

To our knowledge the association of Uhthoff's symptom and glaucoma has not been well recognised. In this series, the following features are common to each case: (1) advanced glaucomatous optic neuropathy in otherwise healthy young adults, (2) exercise of mild to moderate intensity before the onset of symptoms. In addition, in the two cases in which data were available, there was a significant reduction in central visual acuity and depression of overall visual field during exercise with complete or near complete recovery of visual function within $2 \mathrm{~h}$ of cessation of exercise.
In none of the patients was there any clinical evidence of optic neuritis, multiple sclerosis or an optic neuropathy other than glaucoma. Other possible causes of transient bilateral visual loss include migraine, presyncope, epileptic seizures and vertebrobasilar ischaemia. ${ }^{15}$ Exercise-induced migraine presenting with transient visual loss has been described. ${ }^{16}$ However, no patient reported a past or family history of migraine, or positive visual phenomena associated with headache. Pre-syncope is an unlikely mechanism given that none of our patients had a true episode of syncope and the blood pressure and heart rate remained stable during exercise in all cases. In addition, effort syncope characteristically occurs in association with cardiac disease. ${ }^{17}$ The sudden onset of these episodes could be consistent with possible epileptic phenomena. Complete blindness with no other seizure activity has been described, ${ }^{18}$ but none of our 
patients had epilepsy or developed epilepsy during follow-up. Transient vertebrobasilar ischaemic attacks could cause bilateral loss of vision in the absence of other symptoms, but this seems unlikely given the patients' ages and lack of cardiovascular risk factors.

The mechanism for Uhthoff's symptom remains unclear. Hyperthermia, induced for example by taking a hot bath, can cause decreased visual acuity and a reduced amplitude of the $\mathrm{P} 2$ wave of the pattern visual evoked potential in patients with demyelinating optic neuropathy. ${ }^{19}$ However, an exclusively causal role in exercise-related visual loss is unlikely given that symptoms sometimes occur very shortly after light activity insufficient to raise optic nerve temperature. ${ }^{2}$ Because multiple sclerosis is so common in these patients with Uhthoff's symptom, it has been proposed that demyelination of a portion of the optic nerve is the underlying structural component of this phenomenon and may even account for cases associated with other optic neuropathies. ${ }^{2}$ The findings of decreased $\mathrm{pH}$ and lactic acid suggest that a by-product of metabolism alters denuded internodal segments within the optic nerve to produce Uhthoff's symptom. The metabolic effect of exercise is presumed to promote ionic leakage across the demyelinated segment, resulting in reduction of the action current causing conduction to fail. Upon clearance of the by-products of exercise, ionic leakage stops, and conduction is restored.

In addition to exercise-induced visual loss, our patients experienced similar disturbances with consumption of food and alcohol and with sudden changes in head position. This leads us to question whether there may be other explanations for Uhthoff's symptom in these cases. Exercise, eating and drinking could cause a 'vascular steal', with blood from the ocular circulation being shunted to the skin, muscles and gastrointestinal tract. Ocular blood flow could similarly be reduced on head movements by contracting neck muscles compressing the internal carotid artery. In ordinary circumstances, it is unlikely that such minor reductions in blood flow would have an impact on optic nerve function given that it is maintained by an adequate blood supply derived from the central retinal and short posterior retinal arteries. However, if this supply is impaired, as has been demonstrated in patients with glaucoma ${ }^{20,21}$ it is possible that transient oligaemia could result in temporary ganglion cell disturbance and visual loss. In patients with critically perfused optic discs, such as those described in our series, relatively small changes in blood flow can manifest as a dramatic effect in visual function. If a vascular steal phenomenon is, indeed, the underlying aetiology, it is possible that irreversible ischaemia could sustained by individuals who persist with exercise inspite of visual loss.

More work is required to establish the true prevalence of transient exercise-induced visual loss in patients with advanced glaucoma, and to further elucidate the mechanism. Young patients with advanced glaucomatous optic neuropathy should be questioned regarding exercise-induced visual disturbance. Whilst there are no data on the long-term outcome in our cases, it seems logical for patients to refrain from activities which precipitate their symptoms. Additional therapeutic measures to promote ocular blood flow may also be considered, such as aspirin.

\section{References}

1. Uhthoff $W$. Untersuchungen über die Bei der multiplen Herdsklerose vorkommenden Augensturungen. Arch Psychiatr Nervenkr 1890;21:303.

2. Selhorst JB, Saul RF. Uhthoff and his symptom. J NeuroOphthalmol 1995;15:63-9.

3. Nelson DA, Jeffreys WH, McDowell F. Effects of induced hyperthermia on some neurological diseases. Arch Neurol Psychiatry 1955;73:316-23.

4. Lawton Smith J, Hoyt WF, Susac JO. Ocular fundus in acute Leber optic neuropathy. Arch Ophthalmol 1973;90:349-54.

5. Godel V, Nemet P, Lazar M. Chloramphenicol optic neuropathy. Arch Ophthalmol 1980;98:1417-21.

6. Raymond LA, Sacks JG, Choromakos E, Khodadad G. Short posterior ciliary artery insufficiency with hyperthermia. Am J Ophthalmol 1980;90:619-23.

7. Lempert $\mathrm{P}$, Cooper KH, Culver JF. The effect of exercise on intraocular pressure. Am J Ophthalmol 1967;63:1673-6.

8. Harris A, Malinovsky V, Martin B. Correlates of acute exercise-induced ocular hypotension. Invest Ophthalmol Vis Sci 1994;35:3852-7.

9. Smith DL, Kao SF, Rabbani R, Musch DC. The effects of exercise on intraocular pressure in pigmentary glaucoma patients. Ophthalmic Surg 1989;20:561-7.

10. Era P, Parssinen O, Pykala P, Jokela J, Suominen $\mathrm{H}$. Sensitivity of the central visual field in 70- to 81-year-old male athletes and in a population sample. Aging Clin Exp Res 1994;6:335-42.

11. Wood JM, Woods RL, Jack MP. Exercise does not increase visual field sensitivity. Optom Vis Sci 1994;71:682-4.

12. Franklin CR, Brickner RM. Vasospasm associated with multiple sclerosis. Arch Neurol Psychiatry 1947;58:125-62.

13. McAlpine D, Compston N. Some aspects of the natural history of disseminated sclerosis. Q J Med 1952;21:135-67.

14. Edmund J, Fog T. Multiple sclerosis: visual and motor instability. Arch Neurol Psychiatry 1955;76:316-23.

15. Bower S, Dennis M, Warlow C, Jordan N, Sagar H. Long term prognosis of transient lone bilateral blindness in adolescents and young adults. J Neurol Neurosurg Psychiatry 1994;57:734-6.

16. Thomson JK. Exercise-induced migraine prodrome symptoms. Headache 1987;27:250-1.

17. Kumar PJ, Clark ML. Clinical medicine, 2nd ed. London: Bailliere Tindall, 1987:921.

18. Barry E, Sussman NM, Bosley TM, Harner RN. Ictal blindness and status epilepticus amauroticus. Epilepsia 1985;26:577-84.

19. Saul RF, Hayat G, Selhorst JB. Visual evoked potentials during hyperthermia. J Neuro-Ophthalmol 1995;15:70-8.

20. Rojanapongum P, Drance SM, Morrison BJ. Ophthalmic artery flow velocity in glaucomatous and normal subjects. $\mathrm{Br}$ J Ophthalmol 1993;77:25.

21. Rankin JA, Walman BE, Buckley AR, Drance SM. Colour Doppler imaging and spectral analysis of the optic nerve head vasculature in glaucoma. Am J Ophthalmol 1995;119:685. 